\title{
A survey on socioeconomic determinants of diabetes mellitus management in a lower middle income setting
}

\author{
Ambepitiyawaduge Pubudu De Silva ${ }^{1 *}$, Sudirikku Hennadige Padmal De Silva', Rashan Haniffa², \\ Isurujith Kongala Liyanage ${ }^{3}$, Kosala Saroj Amarasiri Jayasinghe ${ }^{4}$, Prasad Katulanda ${ }^{4}$, \\ Chandrika Neelakanthi Wijeratne ${ }^{5}$, Sumedha Wijeratne ${ }^{5}$ and Lalini Chandika Rajapakse ${ }^{1}$
}

\begin{abstract}
Background: Information on socioeconomic determinants in the management of diabetes mellitus is scarce in lower middle income countries. The aim of this study is to describe the socioeconomic determinants of management and complications of diabetes mellitus in a lower middle income setting.

Methods: Cross sectional descriptive study on a stratified random sample of 1300 individuals was conducted by an interviewer administered questionnaire, clinical examinations and blood investigations. A single fasting venous blood sugar of $\geq 126 \mathrm{mg} / \mathrm{dl}$ was considered diagnostic of new diabetics and poor control of diabetes mellitus as $\mathrm{HbA}_{1} \mathrm{C}>6.5 \%$.

Results: There were 202 (14.7\%) with diabetes mellitus. Poor control was seen in 130 (90.7\%) while 71 (49.6\%) were not on regular treatment. Highest proportions of poor control and not on regular medication were observed in estate sector, poorest social status category and poorest geographical area. The annual $\mathrm{HbA}_{1 \mathrm{c}}$ microalbuminuria, retinal and neuropathy examination were performed in less than $6.0 \%$. Social gradient not observed in the management lapses. Most (76.6 \%) had accessed private sector while those in estate (58.1\%) accessed the state system.

The microvascular complications of retinopathy, neuropathy and microalbuminuria observed in $11.1 \%, 79.3 \%$ and $54.5 \%$ respectively. Among the macrovascular diseases, angina, ischaemic heart disease and peripheral arterial disease seen in $15.5 \%, 15.7 \%$ and $5.5 \%$ respectively. These complications do not show a social gradient.

Conclusions: Diabetes mellitus patients, irrespective of their socioeconomic status, are poorly managed and have high rates of complications. Most depend on the private healthcare system with overall poor access to care in the estate sector.
\end{abstract}

Keywords: Diabetes mellitus complications, Diabetes mellitus management, Socioeconomic determinants

\section{Background}

Diabetes mellitus is a global public health problem with a majority in developing countries [1]. In 2008 the agestandardised prevalence of diabetes mellitus for men and women was $9.8 \%(8.6-11.2)$ and $9.2 \%(8.0-10.5)$ respectively, with $40 \%$ of these residing in China and India [1]. The projected increase over the period from 1995-2025

\footnotetext{
* Correspondence: pubududesilva@ymail.com

'Department of Community Medicine, Faculty of Medicine, University of Colombo, No. 25, P.O. Box 271 Kynsey Road, Colombo 08, Sri Lanka Full list of author information is available at the end of the article
}

for developed and developing countries was $42 \%$ and 170 $\%$ respectively [2]. In 2025 it is expected that $75 \%$ of diabetics will reside in developing countries [3].

Diabetes mellitus is a progressive disease requiring effective lifelong medical care for the prevention of secondary and tertiary complications. The optimal control of blood glucose has clearly demonstrated a significant decrease in the development of complications [4]. Control of diabetes mellitus requires the combination of treatment and preventive action, taking into account 
biological and health behavioural factors, health service responsiveness, and socioeconomic conditions [5].

The relationship between socioeconomic positions and the prevalence, management and complications of diabetes mellitus are well known in High Income Countries (HICs) with low socioeconomic status associated with unhealthy behaviours, poor access to care, deficient processes of care and high rate of diabetes complications [6-19].

In Low Income Countries (LICs)/Lower Middle Income Countries (LMICs) the socioeconomic factors are mostly explored in relation to the prevalence of diabetes mellitus while little is known on social determinants of complications and management of this condition [3, 20-24]. According to the World Bank LICs are defined as those with a gross national income per capita of $\$ 1,045$ or less in 2014 while for HICs the figure is $\$ 12,736$ or more [25].The few studies which investigate the complications and management of diabetes mellitus in low and lower middle income settings are usually restricted to hospital attendees $[22,26,27]$. The available data on complications and management of diabetes mellitus in Sri Lanka are limited to state hospital attendees, excluding many patients who obtain services from the private healthcare sector [28-34]. In Sri Lanka the out-patient care for more than $50 \%$ of the population is provided by the private healthcare sector while in-patient care for more than $90 \%$ is provided by the state healthcare sector [35]. State healthcare in Sri Lanka is free at the point of delivery to all citizens of Sri Lanka. This includes all visits/consultations (out-patient as well as inpatient care including intensive care services and surgical care), medications, investigations and procedures including ambulance transportation/transfers and hospital meals.

Understanding the socioeconomic determinants in the management and complications of diabetes mellitus would help to focus measures to address existing issues related diabetes mellitus $[3,36]$. This would further aid to design specific strategies aimed at reducing inequalities and shed more light as to why control measures of diabetes mellitus have failed in South Asian region.

This study is a community based survey to describe the socioeconomic determinants of diabetes mellitus management in a representative sample from a suburban area, in Sri Lanka.

\section{Methods}

A detailed description of the study method is already published [37]. A sample of 1300 individuals between the ages of 35 to 64 years was randomly selected representing the urban, rural and estate sector. The estate sector mainly consists of tea, rubber and coconut plantation sectors and housed to approximately $6 \%$ of Sri Lankans. Compared to urban and rural sectors it is the least resourced and poorest. In this study setting tea and rubber plantation sectors were included.
Data were collected using trained data collectors with validated questionnaires (social status index questionnaire, Rose questionnaire for angina detection and questionnaire to assess neuropathy symptom score \& modified neuropathy disability score) [29, 30, 38, 39]. When administering the questionnaire the participants were simply asked whether they received any information regarding the diseases and if so from whom.

All participants were investigated for diabetes mellitus by conducting fasting plasma glucose (FPG) level using a venous blood sample. The blood samples were obtained after an overnight fast of at least 12 hours. The collected blood samples were analysed at the Public Health Laboratory of National Institute of Health Sciences (Kalutara), using Clini Check Plus Mini Analyser. FPG of $\geq 126 \mathrm{mg} / \mathrm{dl}$ or those who were currently (within the past four weeks) on insulin/hypoglycaemics were considered as having diabetes mellitus [40].

The Unsatisfactory Basic Needs Index (UBNI) developed by Satharasinghe [41] and the social status index developed by De Silva [39] were utilized as measures of socioeconomic matrices. The UBNI is an area level deprivation index calculated taking into consideration the level of education, occupation, housing conditions (wall, roof and floor), source of lighting and cooking. It has a correlation coefficient of 0.62 with the Headcount ratio [41]. The social status index composed of education, occupation, income, assets and social networking. The reliability revealed a Cohen's kappa coefficient $>0.78$ for each item category. The criterion (level of agreement $65 \%$ ) and construct validity (Root Mean Square Error of Approximation $=0.056$ ) were satisfactory [39]. The highest level of education attained was recorded. Those who have passed the General Certificate of Education - Ordinary Level examination (which is held at the end of Grade 10) but has failed to complete the General Certificate of Education -Advanced Level examination was grouped as Ordinary Level to Grade 12 (which includes Grade 11 as well). Those who have passed General Certificate of Education -Advanced Level (which was held at the end of Grade 12) was grouped as Advanced Level and above.

All participants (old and new) diagnosed with diabetes mellitus were assessed by the first author who was trained on clinical examinations of diabetic complications and calibrated against a specialist (Cohen's kappa coefficient 0.7 for diabetic retinopathy). Measures were taken to maintain the quality and accuracy of the data [37].

Diabetic retinopathy was diagnosed by clinical examination. Visual acuity was tested in corrected state, using standard $6 \mathrm{~m}$ Snellen chart for each eye. Patients were asked to bring their spectacles for the eye test. Pinhole correction was used when spectacles were not brought. Fundus examination was carried out by direct ophthalmoscopy performed after pupils were dilated. The patients gaze was fixed away from light except when examining the macular 
areas when they were asked to look directly at the light. Those in the stage of mild nonproliferative retinopathy or above were considered as having diabetic retinopathy. Neuropathy was assessed by a validated neuropathy symptom score and modified neuropathy disability score $[30,33]$. A spot urine albumin was measured in the absence of urinary tract infection, with turbidimetric method using Rx Daytona machine. The presence of urine albumin $>30 \mathrm{mg} / \mathrm{l}$ was considered as microalbuminuria. The presence of diabetic retinopathy, neuropathy or microalbuminuria was considered as having microvascular disease.

Ischaemic Heart Disease (IHD) was diagnosed by 12 lead electrocardiography (ECG) using the Minnesota coding system [42]. Evidence of large Q or QS waves, those with complete left bundle branch block, presence of small Q waves, ST segment abnormalities and $\mathrm{T}$ wave abnormalities were considered as existence of IHD. Angina was diagnosed using the Rose questionnaire [38] and Peripheral Arterial Disease (PAD) was diagnosed using the ankle-brachial pressure index (ABI) [43]. The ABI of 0.91-1.30 was considered as normal. The presence of IHD, angina or PAD was considered as having macrovascular disease.
Diabetic patients who have discontinued medication for more than seven days, on one or more occasions, during the preceding year, were categorized as those who were not on continuous treatment. Visit to a medical professional (state or private sector) on every month during the preceding year was identified as successful monthly follow-ups [44]. Failure to visit on two or more consecutive months was regarded as failure in monthly followups. Self reported impotence, early ejaculation or late ejaculation was considered as having sexual problems. We also documented self reported hypoglycaemic attacks. The control of diabetes was assessed by the levels of glycosylated haemoglobin [45]. Those with glycosylated haemoglobin of more than $6.5 \%$ were considered as having poor control of diabetes mellitus. The use of Benedict's solution at home for detection of reducing substance in urine was inquired from the study participants [46].

Data were analysed using STATA 13. Findings were weighted to make a correction for the over sampling of urban and estate sectors. Results were also adjusted for age and sex of the Sri Lankan population. Standard descriptive statistics was performed. All percentages given

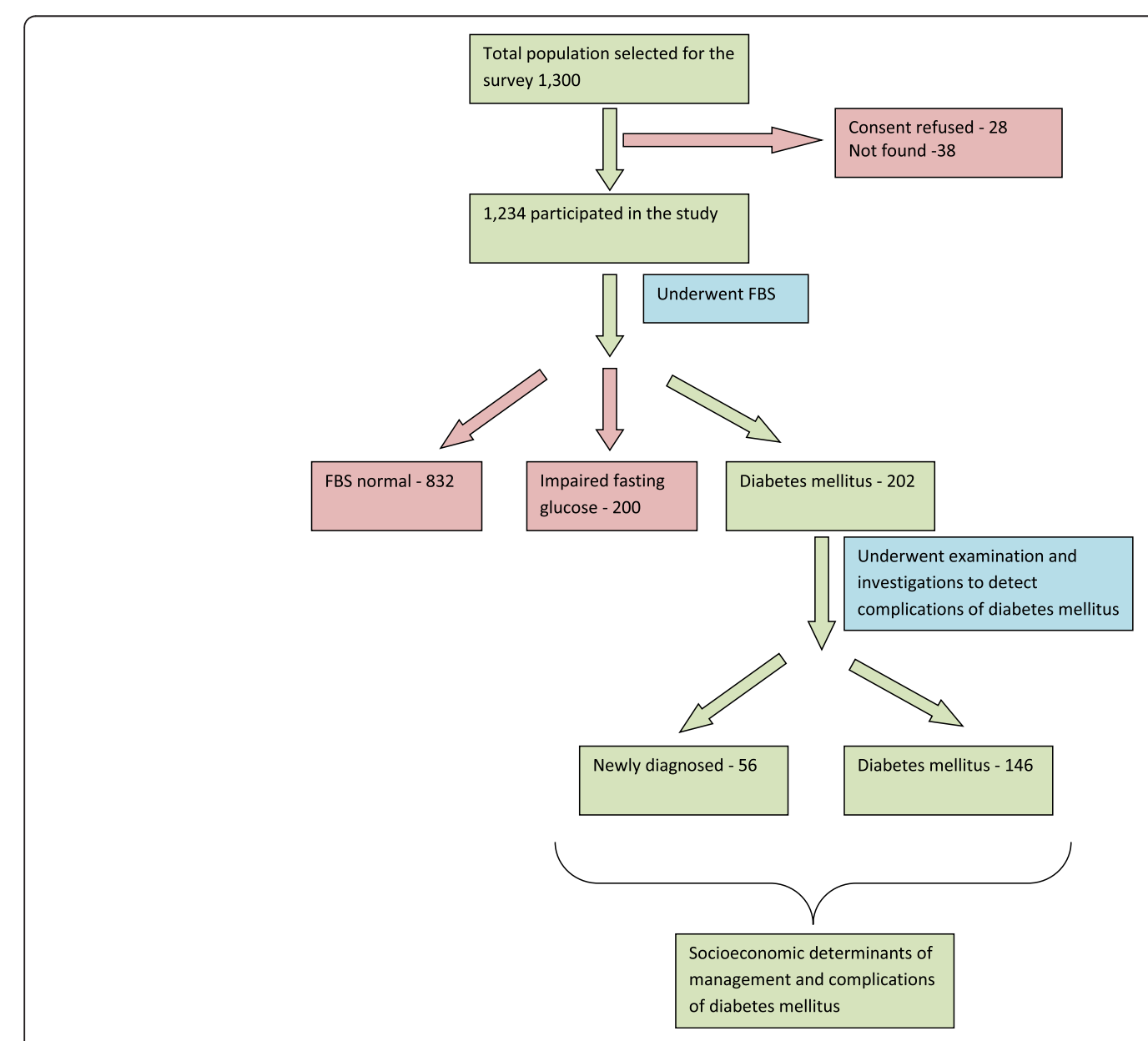

Fig. 1 The flow chart of the study 
in the results sections are expressed as weighted values. Chi square was used to compare discrete variables.

Ethics approval was obtained from the Ethics Review Committee of Faculty of Medicine, University of Colombo (EC/08/119). Informed written consent was obtained from the study participants.

\section{Results}

From the 1,300 selected individuals 1,234 (94.9 \%) participated (Fig. 1). Our previous publication showed that among the participants who were screened (628 males), 202 (14.7\%) had diabetes mellitus [37]; $22.8 \%$ of diabetics (56 individuals) were newly diagnosed.

Of the $146(77.2 \%)$ known to have diabetes mellitus, there were $12(12.1 \%)$ insulin users, and 133 (86 \%) on oral medication for diabetes mellitus while one (1.9) was exclusively on diet control. While most (130, 67.1\%) received information on diet from their treating medical doctor, few $(21,13.2 \%)$ received information on the importance of tight control of blood sugar. Table 1 describes management of already diagnosed individuals with diabetes mellitus $(n=146)$ and the complications among all diabetics $(\mathrm{n}=202)$.

Significant differences $(\mathrm{p}<0.05)$ in the frequency of diabetic retinopathy and ischaemic heart disease were observed between the newly diagnosed (diabetic retinopathy $4.1 \%$, ischaemic heart disease $11.1 \%$ ) and already known diabetes mellitus (diabetic retinopathy $11.5 \%$, ischaemic heart disease $37.6 \%$ ) groups. Almost all complications were higher except neuropathy, among the already known diabetes when compared to the newly diagnosed.

As many as 71 (49.6\%) adults with diabetes mellitus were not on regular medication. Glycaemic control, as defined by $\mathrm{HbA}_{1} \mathrm{C}$, was poor in 130 (90.7\%) adults. Table 2 describes the distribution of diabetes management aspects by socioeconomic characteristics.

There were $42(25.1 \%)$ individuals describing at least one hypoglycaemic attack. One or more microvascular and macrovascular complication was seen in $186(92.1 \%)$ and $56(27.7 \%)$ respectively. Table 3 describes distribution of micro and macrovascular diseases by selected socioeconomic characteristics while Table 4 demonstrates the socioeconomic aspects by place of treatment.

Those attending the private healthcare sector had significantly higher rates of, poor control, poor compliance and poor monthly follow-ups $(\mathrm{p}<0.05)$. Meanwhile those who are attending the state healthcare sector had higher proportion with already diagnosed hypertension and ischaemic heart disease (22, $53.7 \%$ and $10,31.3 \%$ respectively) compared to those visiting the private health sector $(37,44.1 \%$ and $4,3.6 \%$ respectively).
Table 1 Management and complications of individuals with diabetes mellitus

\begin{tabular}{|c|c|c|}
\hline Management and complications & Number & Percentage $^{a}$ \\
\hline \multicolumn{3}{|l|}{ Place of regular visit for treatment $(n=146)$} \\
\hline State & 41 & $23.4 \%$ \\
\hline Private & 100 & $76.6 \%$ \\
\hline Missing & 5 & \\
\hline \multicolumn{3}{|l|}{ Management activities $(n=146)^{b}$} \\
\hline Monthly follow-ups done & 53 & $38.6 \%$ \\
\hline Following a diabetic diet & 16 & $14.4 \%$ \\
\hline Diet control & 16 & $14.4 \%$ \\
\hline Referred to a dietician & 4 & $3.0 \%$ \\
\hline Diet plan by dietician & 1 & $0.1 \%$ \\
\hline Referred to an ophthalmology clinic & 6 & $6.6 \%$ \\
\hline Annual retinal examination & 3 & $4.2 \%$ \\
\hline Neuropathy examination & 0 & $0.0 \%$ \\
\hline \multicolumn{3}{|l|}{ Frequency of investigations conducted $(n=146)^{b}$} \\
\hline Monthly fasting plasma glucose & 62 & $47.2 \%$ \\
\hline Annual plasma lipids & 25 & $13.9 \%$ \\
\hline Annual electrocardiogram & 7 & $4.7 \%$ \\
\hline Annual $\mathrm{HbA}_{1} \mathrm{C}$ & 4 & $2.5 \%$ \\
\hline Annual urine microalbumin & 5 & $5.2 \%$ \\
\hline Benedict's test at home (at least monthly) & 7 & $4.8 \%$ \\
\hline Capillary blood sugar at home (at least monthly) & 5 & $3.6 \%$ \\
\hline \multicolumn{3}{|l|}{ Complications $(n=202)^{b}$} \\
\hline Diabetic retinopathy & 30 & $9.8 \%$ \\
\hline Neuropathy & 159 & $82.9 \%$ \\
\hline Microalbuminurea & 61 & $33.8 \%$ \\
\hline Angina & 35 & $14.4 \%$ \\
\hline Ischaemic heart disease & 29 & $31.7 \%$ \\
\hline Peripheral arterial disease & 8 & $5.1 \%$ \\
\hline Foot ulcer & 22 & $9.0 \%$ \\
\hline Amputation & 2 & $0.1 \%$ \\
\hline $\begin{array}{l}\text { Sexual problems (among males only, } \mathrm{n}=98 \text { ) } \\
\text { (impotence, early/late ejaculation) }\end{array}$ & 43 & $61.6 \%$ \\
\hline
\end{tabular}

${ }^{a}$ All percentages were weighted values, ${ }^{\mathrm{b}}$ Based on multiple responses

\section{Discussion}

Our findings show patients with diabetes mellitus in a suburban region in Sri Lanka continue to be poorly managed with high proportions having microvascular and macrovascular complications, irrespective of socioeconomic factors. These figures, though high when compared to high income countries $[10,11,13,14]$, appear to be comparable to similar settings in Asia and Africa [21, 22, 27].

All previous studies on the management and complications of diabetes mellitus in Sri Lanka over the last three decades were on hospital attendees and demonstrated poor management with high complications [28-34]. Our 
Table 2 The distribution of diabetes mellitus (DM) management aspects by socioeconomic characteristics

\begin{tabular}{|c|c|c|c|c|c|c|c|c|c|c|}
\hline \multirow[t]{2}{*}{ Socioeconomic characteristic } & \multicolumn{2}{|c|}{$\begin{array}{l}\text { Newly diagnosed } \\
\text { with }{ }^{\mathrm{a}} \mathrm{DM}(\mathrm{n}=56)\end{array}$} & \multicolumn{2}{|c|}{$\begin{array}{l}\text { Already diagnosed } \\
\text { of }{ }^{\mathrm{a}} \mathrm{DM}(146)\end{array}$} & \multicolumn{2}{|c|}{$\begin{array}{l}\text { Poor Control of } \\
{ }^{\mathrm{a} D M}(n=130)\end{array}$} & \multicolumn{2}{|c|}{$\begin{array}{l}\text { Not on continuous } \\
\text { treatment }(n=71)\end{array}$} & \multicolumn{2}{|c|}{$\begin{array}{l}\text { Monthly follow-ups } \\
\text { not done }(n=91)\end{array}$} \\
\hline & Number & $\%^{\mathrm{b}}$ & Number & $\%^{\mathrm{b}}$ & Number & $\%^{\mathrm{b}}$ & Number & $\%^{\mathrm{b}}$ & Number & $\%^{\mathrm{b}}$ \\
\hline \multicolumn{11}{|l|}{ Sex } \\
\hline Male & 34 & $27.1 \%$ & 64 & $72.9 \%$ & 58 & $95.8 \%$ & 36 & $55.7 \%$ & 48 & $75.7 \%$ \\
\hline Female & 22 & $19 \%$ & 82 & $81 \%$ & 72 & $86.5 \%$ & 35 & $44.6 \%$ & 43 & $49.5 \%$ \\
\hline \multicolumn{11}{|l|}{ Age (years) } \\
\hline 35 to 39 & 5 & $49.9 \%$ & 6 & $50.1 \%$ & 6 & $100 \%$ & 4 & $51.0 \%$ & 5 & $52.1 \%$ \\
\hline 40 to 44 & 10 & $35.2 \%$ & 19 & $64.8 \%$ & 17 & $89.0 \%$ & 11 & $66.0 \%$ & 13 & $56.4 \%$ \\
\hline 45 to 49 & 13 & $28.7 \%$ & 26 & $71.3 \%$ & 21 & $80.2 \%$ & 13 & $31.4 \%$ & 15 & $50.4 \%$ \\
\hline 50 to 54 & 4 & $0.4 \%$ & 36 & $99.6 \%$ & 35 & $93.5 \%$ & 20 & $65.9 \%$ & 25 & $79.2 \%$ \\
\hline 55 to 59 & 13 & $22 \%$ & 30 & $78 \%$ & 26 & $94.0 \%$ & 11 & $29.5 \%$ & 15 & $49.8 \%$ \\
\hline 60 to 64 & 11 & $22.7 \%$ & 29 & $77.2 \%$ & 25 & $92.3 \%$ & 12 & $52.9 \%$ & 18 & $65.4 \%$ \\
\hline \multicolumn{11}{|l|}{ Ethnicity } \\
\hline Sinhalese & 40 & $23.9 \%$ & 116 & $76.1 \%$ & 103 & $91.9 \%$ & 59 & $51.2 \%$ & 72 & $63.6 \%$ \\
\hline Tamil & 11 & $7.3 \%$ & 12 & $92.7 \%$ & 11 & $99.0 \%$ & 6 & $4.2 \%$ & 8 & $5.6 \%$ \\
\hline Muslim & 5 & $3.3 \%$ & 18 & $96.7 \%$ & 15 & $67.1 \%$ & 6 & $33.1 \%$ & 11 & $37.0 \%$ \\
\hline \multicolumn{11}{|l|}{ Education } \\
\hline No schooling & 4 & $2.2 \%$ & 2 & $97.8 \%$ & 1 & $41.0 \%$ & - & - & - & - \\
\hline Grade 5 or below & 9 & $35.2 \%$ & 23 & $64.8 \%$ & 21 & $99.3 \%$ & 9 & $24.0 \%$ & 9 & $47.6 \%$ \\
\hline Grade 6 to Grade 10 & 24 & $21.3 \%$ & 55 & $78.7 \%$ & 52 & $97.5 \%$ & 25 & $47.4 \%$ & 33 & $52.6 \%$ \\
\hline Ordinary Level to Grade 12 & 14 & $8.3 \%$ & 30 & $91.7 \%$ & 26 & $90.5 \%$ & 17 & $53.0 \%$ & 23 & $73.5 \%$ \\
\hline Advanced Level and above & 4 & $23.4 \%$ & 27 & $76.6 \%$ & 24 & $93.4 \%$ & 17 & $64.8 \%$ & 19 & $70.8 \%$ \\
\hline Missing & 1 & & 9 & & 3 & & 3 & & 7 & \\
\hline \multicolumn{11}{|l|}{ Occupation } \\
\hline Professional & 1 & $34 \%$ & 2 & $66 \%$ & 2 & $100 \%$ & 2 & $100 \%$ & 2 & $100 \%$ \\
\hline Technical \& clerical & 3 & $3 \%$ & 9 & $97 \%$ & 9 & $100 \%$ & 7 & $79.5 \%$ & 8 & $98.9 \%$ \\
\hline Vendors and sellers & 10 & $18.7 \%$ & 23 & $81.3 \%$ & 23 & $100 \%$ & 11 & $43.7 \%$ & 18 & $74.2 \%$ \\
\hline Skilled manual workers & 8 & $35.3 \%$ & 15 & $64.7 \%$ & 10 & $82.5 \%$ & 11 & $64.6 \%$ & 9 & $63.8 \%$ \\
\hline Unskilled manual workers & 13 & $34.6 \%$ & 10 & $65.4 \%$ & 10 & $100 \%$ & 6 & $58.6 \%$ & 8 & $99.5 \%$ \\
\hline Retired & 2 & $1.2 \%$ & 11 & $98.8 \%$ & 10 & $99.4 \%$ & 4 & $47.5 \%$ & 6 & $48.2 \%$ \\
\hline Unemployed & 2 & $40.8 \%$ & 9 & $59.2 \%$ & 9 & $100 \%$ & 4 & $62.3 \%$ & 6 & $63.6 \%$ \\
\hline Housewife & 16 & $21.4 \%$ & 66 & $78.6 \%$ & 56 & $83.9 \%$ & 26 & $43.3 \%$ & 33 & $46.5 \%$ \\
\hline Missing & 1 & & 1 & & 0 & & 0 & & 1 & \\
\hline \multicolumn{11}{|l|}{ Sector } \\
\hline Urban & 25 & $26.5 \%$ & 65 & $73.5 \%$ & 57 & $89.0 \%$ & 31 & $47.6 \%$ & 40 & $62.6 \%$ \\
\hline Rural & 20 & $22.6 \%$ & 68 & $77.4 \%$ & 61 & $90.8 \%$ & 32 & $49.6 \%$ & 41 & $61.3 \%$ \\
\hline Estate & 11 & $46.4 \%$ & 13 & $53.6 \%$ & 12 & $89.4 \%$ & 08 & $59.4 \%$ & 10 & $75.8 \%$ \\
\hline \multicolumn{11}{|l|}{ Income Category (Monthly Income) } \\
\hline < Sri Lankan Rupees 10,000 & 16 & $23.4 \%$ & 37 & $76.6 \%$ & 33 & $99.5 \%$ & 13 & $35.8 \%$ & 18 & $52.0 \%$ \\
\hline Sri Lankan Rupees 10,000 to 30,000 & 32 & $24.4 \%$ & 78 & $75.6 \%$ & 70 & $89.6 \%$ & 44 & $59.9 \%$ & 50 & $66.9 \%$ \\
\hline > Sri Lankan Rupees 30,000 & 5 & $9.8 \%$ & 29 & $90.2 \%$ & 26 & $85.1 \%$ & 14 & $40.6 \%$ & 23 & $66.7 \%$ \\
\hline
\end{tabular}


Table 2 The distribution of diabetes mellitus (DM) management aspects by socioeconomic characteristics (Continued)

\begin{tabular}{|c|c|c|c|c|c|c|c|c|c|c|}
\hline Missing & 3 & & 2 & & 1 & & 0 & & 0 & \\
\hline \multicolumn{11}{|l|}{ Social status index } \\
\hline $1^{\text {st }}$ quintile (richest) & 8 & $18.2 \%$ & 39 & $81.8 \%$ & 33 & $92.5 \%$ & 20 & $43.2 \%$ & 23 & $60.8 \%$ \\
\hline $2^{\text {nd }}$ quintile & 13 & $28.2 \%$ & 38 & $71.8 \%$ & 37 & $99.8 \%$ & 13 & $30.1 \%$ & 18 & $37.7 \%$ \\
\hline $3^{\text {rd }}$ quintile & 14 & $23.9 \%$ & 31 & $76.1 \%$ & 25 & $79.0 \%$ & 20 & $69.2 \%$ & 23 & $66.5 \%$ \\
\hline $4^{\text {th }}$ quintile & 12 & $21.4 \%$ & 30 & $78.6 \%$ & 27 & $92.0 \%$ & 14 & $57.3 \%$ & 22 & $81.0 \%$ \\
\hline $5^{\text {th }}$ quintile (poorest) & 9 & $53 \%$ & 8 & $47 \%$ & 8 & $100.0 \%$ & 4 & $51.5 \%$ & 5 & $60.9 \%$ \\
\hline \multicolumn{11}{|c|}{ Unsatisfactory Basic Needs Index } \\
\hline 1 (poorest) & 6 & $99.1 \%$ & 2 & $0.9 \%$ & 2 & $100.0 \%$ & 1 & $50.8 \%$ & 1 & $50.8 \%$ \\
\hline 2 & 5 & $94.9 \%$ & 8 & $5.1 \%$ & 8 & $100.0 \%$ & 6 & $82.6 \%$ & 7 & $90.6 \%$ \\
\hline 3 & 8 & $15.1 \%$ & 20 & $84.9 \%$ & 16 & $81.9 \%$ & 12 & $60.2 \%$ & 11 & $56.0 \%$ \\
\hline 4 & 17 & $28.4 \%$ & 47 & $71.6 \%$ & 44 & $99.6 \%$ & 19 & $52.5 \%$ & 31 & $67.3 \%$ \\
\hline 5 (richest) & 20 & $22 \%$ & 69 & $82 \%$ & 60 & $91.0 \%$ & 33 & $41.1 \%$ & 41 & $61.2 \%$ \\
\hline \multicolumn{11}{|l|}{ Place of management } \\
\hline State & - & - & 41 & $23.4 \%$ & 33 & $79.9 \%$ & 12 & $23.7 \%$ & 10 & $9 \%$ \\
\hline Private & - & - & 100 & $76.6 \%$ & 93 & $93.8 \%$ & 56 & $57 \%$ & 77 & $76.8 \%$ \\
\hline Missing & - & - & 5 & & 4 & & 3 & & 4 & \\
\hline
\end{tabular}

${ }^{a} \mathrm{DM}$, diabetes mellitus

${ }^{b}$ All percentages were weighted values

survey, on the contrary captures all hospital attendees, non-hospital attendees and irregular hospital attendees, for a condition predominantly managed in the community, and shows that over the last two decades there have been no improvements in the care of patients (in hospital settings) with diabetes mellitus compared to previous studies. This is true across all socioeconomic categories.

The hospital based studies in Sri Lanka reported lesser proportions with macro and microvascular complications compared to our findings since these have failed to capture non clinic attendees and private sector patients [28-34]. Similar to previous studies commonest macrovascular complication is ischaemic heart disease while the commonest microvascular is peripheral neuropathy [28, 30, 31, 33, 47-49].

Past studies on government hospital based populations in Sri Lanka, have highlighted poor management and control of diabetes mellitus among clinic attendees of these hospitals [48-50]. This study further establishes that those who were managed by the state as well as the private sector are poorly managed.

We demonstrate that the screening of diabetic complications is being performed only in a minority even when the disease is well established, irrespective of the socioeconomic background of the patient. The reasons for such low levels of screening are unclear and needs further exploration. The possible reasons include lack of awareness of doctors, moving between doctors, poor record keeping, poor patient compliance, costs of investigations amongst others.
The poor screening is reinforced by the fact that the already diagnosed with diabetes mellitus have high proportions with complication such as diabetic retinopathy; conditions which arise due to prolonged uncontrolled state of the disease [4].

Perhaps the most surprising new finding from our study is that overall poor management and complications of diabetes mellitus seem to cut across all socioeconomic groups and do not appear to show a detectable social gradient. This is in contrast to high income countries, where prevalence, poor management and complications of diabetes show a social gradient with higher proportion observed among the lower socioeconomic groups [10,11, 13, 14, 17-19]. Our previous publication, meanwhile, showed an inverse social gradient in the prevalence of diabetes mellitus, which is also in contrary to high income settings [37]. These disparities in diabetes mellitus prevalence, management and its compilations may indicate that Sri Lanka is in a transitional stage. Studies from Sri Lanka including the present study, do not show clear evidence of the increased prevalence of diabetes and cardiovascular disease in lower socioeconomic groups compared to higher socio-economic groups [37, 49, 51-53]. This contrasts with experience from the UK, Western Europe and North America where a gradient in mortality across socio-economic groups was observed, i.e. poorer groups affected more by ill-health compared to more affluent groups [54-58]. However, a pattern similar to the current situation in Sri Lanka was observed in England and Wales prior to 1960 when 
Table 3 The distribution of micro and macrovascular diseases by socioeconomic characteristics

\begin{tabular}{|c|c|c|c|c|}
\hline \multirow[t]{3}{*}{ Socioeconomic characteristic } & \multicolumn{4}{|c|}{$\begin{array}{l}\text { Complications of diabetes mellitus } \\
(\mathrm{n}=202)^{\mathrm{a}}\end{array}$} \\
\hline & \multicolumn{2}{|c|}{$\begin{array}{l}\text { Microvascular } \\
(n=186)\end{array}$} & \multicolumn{2}{|c|}{$\begin{array}{l}\text { Macrovascular } \\
(n=56)\end{array}$} \\
\hline & Number & $\%^{\mathrm{b}}$ & Number & $\%^{\mathrm{b}}$ \\
\hline \multicolumn{5}{|l|}{ Sex } \\
\hline Male & 92 & $91.0 \%$ & 20 & $12.5 \%$ \\
\hline Female & 94 & $93.1 \%$ & 36 & $35.3 \%$ \\
\hline \multicolumn{5}{|l|}{ Age (years) } \\
\hline 35 to 39 & 11 & $100 \%$ & 1 & $0.8 \%$ \\
\hline 40 to 44 & 26 & $99.4 \%$ & 2 & $7.0 \%$ \\
\hline 45 to 49 & 34 & $85.6 \%$ & 13 & $42.4 \%$ \\
\hline 50 to 54 & 34 & $80.4 \%$ & 14 & $20.6 \%$ \\
\hline 55 to 59 & 43 & $100 \%$ & 18 & $35.0 \%$ \\
\hline 60 to 64 & 38 & $94.6 \%$ & 8 & $22.3 \%$ \\
\hline \multicolumn{5}{|l|}{ Ethnicity } \\
\hline Sinhalese & 144 & $93.1 \%$ & 37 & $23.4 \%$ \\
\hline Tamil & 20 & $97.6 \%$ & 15 & $93.9 \%$ \\
\hline Muslim & 22 & $69.0 \%$ & 4 & $32.8 \%$ \\
\hline \multicolumn{5}{|l|}{ Education } \\
\hline No schooling & 5 & $42.4 \%$ & 4 & $58.5 \%$ \\
\hline Grade 5 or below & 29 & $92.8 \%$ & 17 & $43.2 \%$ \\
\hline Grade 6 to Grade 10 & 73 & $99.4 \%$ & 17 & $24.7 \%$ \\
\hline Ordinary Level to Grade 12 & 42 & $88.4 \%$ & 7 & $11.8 \%$ \\
\hline Advanced Level and above & 28 & $86.2 \%$ & 7 & $18.5 \%$ \\
\hline Missing & 9 & & 4 & \\
\hline \multicolumn{5}{|l|}{ Occupation } \\
\hline Professional & 2 & $46.0 \%$ & 1 & $34.0 \%$ \\
\hline Technical \& clerical & 11 & $71.6 \%$ & 1 & $0.6 \%$ \\
\hline Vendors and sellers & 31 & $86.4 \%$ & 6 & $11.2 \%$ \\
\hline Skilled manual workers & 22 & $99.9 \%$ & 2 & $11.5 \%$ \\
\hline Unskilled manual workers & 22 & $99.8 \%$ & 11 & $32.9 \%$ \\
\hline Retired & 13 & $100 \%$ & 1 & $0.7 \%$ \\
\hline Unemployed & 11 & $100 \%$ & 3 & $21.6 \%$ \\
\hline Housewife & 72 & $92.1 \%$ & 30 & $37.3 \%$ \\
\hline Missing & 2 & & 1 & \\
\hline \multicolumn{5}{|l|}{ Sector } \\
\hline Urban & 83 & $91.1 \%$ & 20 & $20.7 \%$ \\
\hline Rural & 82 & $92.2 \%$ & 22 & $24.6 \%$ \\
\hline Estate & 21 & $85.0 \%$ & 14 & $53.6 \%$ \\
\hline \multicolumn{5}{|l|}{ Income Category (Monthly Income) } \\
\hline < Sri Lankan Rupees 10,000 & 47 & $92.1 \%$ & 20 & $30.4 \%$ \\
\hline Sri Lankan Rupees 10,000 to 30,000 & 101 & $90.4 \%$ & 28 & $22.6 \%$ \\
\hline
\end{tabular}

Table 3 The distribution of micro and macrovascular diseases by socioeconomic characteristics (Continued)

\begin{tabular}{lllll}
\hline$>$ Sri Lankan Rupees 30,000 & 33 & $99.7 \%$ & 5 & $1.1 \%$ \\
$\quad$ Missing & 5 & & 3 & \\
Social status index & & & & \\
$1^{\text {st }}$ quintile (richest) & 44 & $95.1 \%$ & 14 & $36.6 \%$ \\
$2^{\text {nd }}$ quintile & 48 & $93.9 \%$ & 12 & $23.8 \%$ \\
$3^{\text {rd }}$ quintile & 44 & $94.7 \%$ & 9 & $15.1 \%$ \\
$4^{\text {th }}$ quintile & 35 & $83.5 \%$ & 9 & $20.2 \%$ \\
$5^{\text {th }}$ quintile (poorest) & 15 & $87.9 \%$ & 12 & $66.9 \%$ \\
Unsatisfactory Basic Needs Index & & & & \\
1 (poorest) & 6 & $99.1 \%$ & 4 & $1.4 \%$ \\
2 & 12 & $99.5 \%$ & 7 & $5.0 \%$ \\
3 & 26 & $92.0 \%$ & 8 & $19.7 \%$ \\
4 & 58 & $89.3 \%$ & 12 & $16.5 \%$ \\
5 (richest) & 84 & $93.5 \%$ & 25 & $34.3 \%$ \\
Place of management $(\mathrm{n}=146)$ & & & & \\
State & 36 & $91.8 \%$ & 21 & $50.2 \%$ \\
Private & 94 & $90.4 \%$ & 17 & $18.7 \%$ \\
Missing & 5 & & 5 & \\
\hline
\end{tabular}

aPresence of one or more complications were considered; ${ }^{\mathrm{b}} \mathrm{All}$ percentages were weighted values

poorer social classes had lower risk of death from coronary heart disease than the higher classes [59]. It is therefore hypothesized that Sri Lanka too is undergoing this transition and the current status is a point in time when the gradient in adverse outcomes appears to be equal across socio-economic groups.

Interestingly higher proportion of microvascular diseases was observed among higher socioeconomic groups while higher proportion of macrovascular diseases was seen among the lower socioeconomic groups. A social gradient is only observed for macrovascular complications within sector and income category. These observations may be due to the co-existing socioeconomic inequality of cardiovascular diseases, which requires further investigation.

The estate sector (the most disadvantaged setting in the country) [60], poorest SSI category and the poorest UBNI category, had the highest proportion of poor control, poor follow-up and not on continuous treatment for diabetes mellitus. Macrovascular complications were seen again most among the estate sector, lowest income group and the poorest SSI category.

Access to private healthcare was high for all socioeconomic strata, except those in the estate sector, despite universal free health care at the point of delivery in the country. In most LICs/LMICs and HICs majority with diabetes mellitus accessed the state sector [22, 26, 27, 61, 62]. Possible reasons for accessing the private healthcare sector 
Table 4 The distribution of socioeconomic characteristics by place of treatment

\begin{tabular}{|c|c|c|c|c|}
\hline \multirow[t]{2}{*}{ Socioeconomic characteristic } & \multicolumn{2}{|c|}{ State $(n=41)$} & \multicolumn{2}{|c|}{ Private (100) } \\
\hline & Number & $\%^{a}$ & Number & $\%^{\mathrm{a}}$ \\
\hline \multicolumn{5}{|l|}{ Sex } \\
\hline Male & 14 & $16.6 \%$ & 50 & $83.4 \%$ \\
\hline Female & 27 & $29.2 \%$ & 50 & $70.8 \%$ \\
\hline \multicolumn{5}{|l|}{ Age (years) } \\
\hline 35 to 39 & 1 & $47.9 \%$ & 5 & $52.1 \%$ \\
\hline 40 to 44 & 2 & $21.5 \%$ & 16 & $78.5 \%$ \\
\hline 45 to 49 & 6 & $20.1 \%$ & 19 & $79.9 \%$ \\
\hline 50 to 54 & 15 & $20.9 \%$ & 21 & $79.1 \%$ \\
\hline 55 to 59 & 10 & $28.1 \%$ & 19 & $71.9 \%$ \\
\hline 60 to 64 & 7 & $19.2 \%$ & 20 & $80.8 \%$ \\
\hline \multicolumn{5}{|l|}{ Ethnicity } \\
\hline Sinhalese & 28 & $21.8 \%$ & 84 & $78.2 \%$ \\
\hline Tamil & 8 & $97.6 \%$ & 3 & $2.4 \%$ \\
\hline Muslim & 5 & $34.7 \%$ & 13 & $65.3 \%$ \\
\hline \multicolumn{5}{|l|}{ Education } \\
\hline No schooling & 1 & $59.0 \%$ & 1 & $41.0 \%$ \\
\hline Grade 5 or below & 11 & $19.4 \%$ & 10 & $80.6 \%$ \\
\hline Grade 6 to Grade 10 & 21 & $42.4 \%$ & 33 & $57.6 \%$ \\
\hline Ordinary Level to Grade 12 & 4 & $0.6 \%$ & 26 & $99.4 \%$ \\
\hline Advanced Level and above & 2 & $11.1 \%$ & 25 & $88.9 \%$ \\
\hline Missing & 2 & & 5 & \\
\hline \multicolumn{5}{|l|}{ Occupation } \\
\hline Professional & - & - & 2 & $100 \%$ \\
\hline Technical \& clerical & - & - & 9 & $100 \%$ \\
\hline Vendors and sellers & 2 & $5.6 \%$ & 21 & $94.4 \%$ \\
\hline Skilled manual workers & 4 & $35.0 \%$ & 11 & $65.0 \%$ \\
\hline Unskilled manual workers & 3 & $0.8 \%$ & 5 & $99.2 \%$ \\
\hline Retired & 5 & $37.4 \%$ & 6 & $62.6 \%$ \\
\hline Unemployed & 4 & $37.5 \%$ & 5 & $62.5 \%$ \\
\hline Housewife & 23 & $31.9 \%$ & 40 & $68.1 \%$ \\
\hline Missing & 0 & & 1 & \\
\hline \multicolumn{5}{|l|}{ Sector } \\
\hline Urban & 19 & $28.8 \%$ & 44 & $71.2 \%$ \\
\hline Rural & 15 & $23.2 \%$ & 51 & $76.8 \%$ \\
\hline Estate & 7 & $58.1 \%$ & 5 & $41.9 \%$ \\
\hline \multicolumn{5}{|l|}{ Income Category (Monthly Income) } \\
\hline < Sri Lankan Rupees 10,000 & 16 & $31.6 \%$ & 17 & $68.4 \%$ \\
\hline Sri Lankan Rupees 10,000 to 30,000 & 20 & $20.3 \%$ & 57 & $79.7 \%$ \\
\hline > Sri Lankan Rupees 30,000 & 4 & $16.6 \%$ & 15 & $83.4 \%$ \\
\hline Missing & 1 & & 11 & \\
\hline
\end{tabular}

Table $\mathbf{4}$ The distribution of socioeconomic characteristics by place of treatment (Continued)

\begin{tabular}{lllll}
\hline Social status index & & & & \\
$1^{\text {st }}$ quintile (richest) & 9 & $21.1 \%$ & 30 & $78.9 \%$ \\
$2^{\text {nd }}$ quintile & 14 & $44.3 \%$ & 23 & $55.7 \%$ \\
$3^{\text {rd }}$ quintile & 5 & $13.7 \%$ & 26 & $86.3 \%$ \\
$4^{\text {th }}$ quintile & 8 & $15.6 \%$ & 18 & $84.4 \%$ \\
$5^{\text {th }}$ quintile (poorest) & 5 & $61.2 \%$ & 3 & $38.8 \%$ \\
Unsatisfactory Basic Needs Index & & & & \\
1 (poorest) & 1 & $49.2 \%$ & 1 & $50.8 \%$ \\
2 & 4 & $40.3 \%$ & 3 & $59.7 \%$ \\
3 & 5 & $30.2 \%$ & 13 & $69.8 \%$ \\
4 & 14 & $16.8 \%$ & 32 & $83.2 \%$ \\
5 (richest) & 17 & $23.1 \%$ & 51 & $76.9 \%$ \\
\hline a All percentages
\end{tabular}

${ }^{\mathrm{a} A l l}$ percentages were weighted values

are due to likelihood of follow-up by same doctor, reduced waiting times, fewer queues and less congestion, easy accessibility to the private sector specialists due to the absence of a referral system and convenience in terms time of consulting without disruption to work.

However those living in the estate sector seem to utilize mostly the state sector. The main reasons likely to be are the economic and geographical constraints in accessing the private healthcare sector. Perhaps surprisingly the prevalence of microvascular complications in this group is not very different to urban and rural sector. However the high proportion of macrovascular complications can be attributed to co-existing cardiovascular diseases.

Diabetes mellitus patients utilising government healthcare appear to be better managed compared to the private sector even though the microvascular complications were equal in both groups. Although in the state sector there are different levels of care, within each level it is likely to be uniform with less variation in care. Staffing is similar at these levels and is from the same pool of people, whereas in the private sector it is more variable. The quality of state sector services are probably better (though it may be lower than the standard care) due to a number of reasons. One reason could be because the staffing of the state sector hospitals and clinics are administratively accountable to minimum standards or record keeping and documentation. In contrast, the private sector has a wide range or personnel who service their needs. They range from parttime government employed staff or those who work as locums. This tends to fragment their services and follow-up as records are rarely kept. The short-term management as evidenced by $\mathrm{HbA}_{1} \mathrm{C}$ levels may therefore appear to be different between the two sectors. However, in the longterm, the difference may be blurred by patients shifting from one to the other sector and therefore microvascular 
outcomes may become similar. Also the participants may make return visits to the government sector for follow-up as it is free. Further investigations are required to explore reasons for these observations. In addition strict adherence to the protocols given by the Ministry of Health, Sri Lanka may also help to reduce the high complication rates [44].

Another important finding of this study was that the undetected diabetes mellitus proportion is decreasing. Previous studies in the country have reported undetected proportions higher than $35 \%$ [51, 52]. In South Asia and Africa regions the undetected proportion exceeds more than half the diabetes population $[21,22]$. This can be attributed to the opportunistic screening done in both private and state healthcare sectors. High proportion of newly detected in estates, $5^{\text {th }}$ SSI group (lowest social status index category) and $1^{\text {st }}$ UBNI group (poorest UBNI group) indicates that these groups may get less prospects for opportunistic screening. The estate sector had the highest proportion of newly diagnosed suggesting that screening should be targeted to this population.

In most European and Northern American states, the prevalence of diabetes mellitus and its complications show a social gradient with higher rates in those with lower socioeconomic status, lower income levels and poorer educational achievements $[5,7,13,17,19,48,63$, 64]. In these HICs the socioeconomic differences often also exist in accessing health care, though there are exceptions $[8,16]$.

Major limitation of the study was the cross sectional nature to investigate a disease with long-term complications. The potential confounding variables that were not measured were psychosocial work characteristics, psychiatric morbidity and life events is another limitation.

Interestingly our findings suggest a crucial difference with high prevalence of complications and poor control of diabetes mellitus across all socioeconomic strata possibly because of the poor quality of screening and deficiencies in adhering to guidelines and protocols. However the reasons contributing to this merit further study including those of service improvements targeting groups such as estates. In addition, it should be explored why patients are discontinuing treatment and not regularly attending the follow-up clinics.

\section{Conclusion}

The vast majority of patients with diabetes mellitus are poorly managed and most had poor control of the disease. Greater proportion of them has microvascular and macrovascular complications and during the medical management most are not screened for these complications. Although majority of poor management and complications observed in the poor geographical and poor social status groups overall socioeconomic gradient seems to be absent with regard to the management and complications of diabetes mellitus.

\section{Abbreviations}

ABI: Ankle-Brachial pressure Index; ECG: Electrocardiography; HIC: High Income Country; IHD: Ischaemic Heart Disease; LIC: Low Income Country; LMIC: Lower Middle Income Country; PAD: Peripheral Arterial Disease; UBNI: Unsatisfactory Basic Needs Index.

\section{Competing interests}

The authors declare that they have no competing interests.

\section{Authors' contributions}

APDS gave the original idea, developed the methodology, conducted the training and validation of data collection, data analysis and writing of the manuscript. SHPDS developed the methodology, supervised data collection, conducted analysis and writing the manuscript. $\mathrm{RH}$ developed the methodology, data analysis and writing of the manuscript. IKL developed the methodology, supervised data collection, conducted analysis and writing the manuscript. KSAJ also gave the original idea, developed the methodology, data analysis and writing of the manuscript. PK developed the methodology, data analysis and writing of the manuscript.CNW developed the

methodology, data analysis and writing of the manuscript. SW developed the methodology, data analysis and writing of the manuscript. LCR also gave the original idea, developed the methodology, data analysis and writing of the manuscript. All authors read and approved the final manuscript.

\section{Acknowledgements}

The study was funded by the National Health Research Council of Sri Lanka. The authors are thankful to the staff of the National Institute of Health Sciences, Kalutara and all Primary Healthcare Staff of Kalutara Regional Director of Health Services for the immense support rendered.

A. Pubudu De Silva, S.H. Padmal De Silva and Isurujith K. Liyanage were supported by the ASCEND Program (www.med.monash.edu.au/ascend) funded by the Fogarty International Centre, National Institutes of Health, under Award Number: D43TW008332. The contents of this publication is solely the responsibility of the authors and does not necessarily represent the official views of the National Institutes of Health or the ASCEND Program.

\section{Author details}

${ }^{1}$ Department of Community Medicine, Faculty of Medicine, University of Colombo, No. 25, P.O. Box 271 Kynsey Road, Colombo 08, Sri Lanka. ${ }^{2}$ Centre for Tropical Medicine, University of Oxford, Oxford, UK. ${ }^{3}$ Department of Para Clinical Sciences, Faculty of Medicine, General Sir John Kotelawala University, Colombo, Sri Lanka. ${ }^{4}$ Department of Clinical Medicine, Faculty of Medicine, University of Colombo, Colombo, Sri Lanka. ${ }^{5}$ Department of Obstetrics \& Gynaecology, Faculty of Medicine, University of Colombo, Colombo, Sri Lanka.

Received: 24 December 2015 Accepted: 27 April 2016

Published online: 04 May 2016

\section{References}

1. Danaei G, Finucane MM, Lu Y, Singhe GM, Cowan MJ, Paciorek CJ, et al. National, regional, and global trends in fasting plasma glucose and diabetes prevalence since 1980: systematic analysis of health examination surveys and epidemiological studies with 370 country-years and 2.7 million participants. Lancet. 2011;378:31-40.

2. King H, Aubert RE, Herman WH. Global burden of diabetes, 1995-2025: prevalence, numericl estimates, and projections. Diabetes Care. 1998;21:1414-31.

3. Dagogo-Jack S. Primary prevention of type-2 diabetes in developing countries. J Natl Med Assoc. 2006;98:415-9.

4. Stratton IM, Adler Al, Neil HAW, Matthews DR, Manley SE, Cull CA, et al. Association of glycaemia with macrovascular and microvascular complications of type 2 diabetes (UKPDS 35): prospective observational study. BMJ. 2000;321:405-12.

5. Bachmann MO, Eachus J, Hopper CD, Davey Smith G, Propper C, Pearson $\mathrm{NJ}$, et al. Socio-economic inequalities in diabetes complications, control, attitudes and health service use: a cross-sectional study. Diabet Med. 2003; 20:921-9. 
6. Matsushima M, Shimizu K, Maruyama M, Nishimura R, LaPorte RE, Tajima N Socioeconomic and behavioural risk factors for mortality of individuals with IDDM in Japan: population-based case-control study. Diabetes Epidemiology Research International (DERI) US-Japan Mortality Study Group. Diabetologia. 1996;39:710-6.

7. Chaturvedi N, Jarrett J, Shipley MJ, Fuller JH. Socioeconomic gradient in morbidity and mortality in people with diabetes: cohort study findings from the Whitehall study and the WHO multinational study of vascular disease in diabetes. BMJ. 1998;316:100-5.

8. Koskinen SV, Martelin TP, Valkonen T. Socioeconomic differences in mortality among diabetic people in Finland: five year follow up. BMJ. 1996;313:975-8

9. Robinson N, Lloyd CE, Stevens LK. Social deprivation and mortality in adults with diabetes mellitus. Diabet Med. 1998;15:205-12.

10. Wild SH, McKnight JA, McConnachie A, Lindsay RS. Socioeconomic status and diabetes-related hospital admissions: a cross-sectional study of people with diagnosed diabetes. J Epidemiol Community Health. 2010;64:1022-4.

11. Weng C, Coppini DV, Sonksen PH. Geographic and social factors are related to increased morbidity and mortality rates in diabetic patients. Diabet Med. 2000;17:612-7.

12. Roper NA, Bilous RW, Kelly WF, Unwin NC, Connolly VM. Excess mortality in a population with diabetes and the impact of material deprivation: longitudinal, population based study. BMJ. 2001;322:1389-93.

13. Chaturvedi N, Stephenson JM, Fuller JH. The relationship between socioeconomic status and diabetes control and complications in the EURODIAB IDDM Complications Study. Diabetes Care. 1996:19:423-30.

14. Klein $\mathrm{R}$, Klein BE, Jensen SC, Moss SE. The relation of socioeconomic factors to the incidence of proliferative diabetic retinopathy and loss of vision. Ophthalmology. 1994;101:68-76.

15. Haffner SM, Hazuda HP, Stern MP, Patterson JK, Heuven WAJV, Fong D. Effects of socioeconomic status on hyperglycemia and retinopathy levels in Mexican Americans with NIDDM. Diabetes Care. 1989;12:128-34.

16. Harris MI. Racial and ethnic differences in health care access and health outcomes for adults with type 2 diabetes. Diabetes Care. 2001;24:454-9.

17. Ricci-Cabello I, Ruiz-Pérez I, Olry de Labry-Lima A, Márquez-Calderón S. Do social inequalities exist in terms of the prevention, diagnosis, treatment, control and monitoring of diabetes? A systematic review. Health Soc Care Community. 2010;18:572-87.

18. Mold F, While A, Forbes A. The management of type 2 diabetes care: the challenge within primary care. Practical Diabetes Int. 2008;25:28-36.

19. Hsu CC, Lee CH, Wahlgvist ML, Huang HL, Chang HY, Chen L, et al. Poverty increases type 2 diabetes incidence and inequality of care despite universal health coverage. Diabetes Care. 2012;35:2286-92.

20. Bhowmik B, Afsana F, Diep LM, Munir SB, Wright E, Mahmood S, et al Increasing Prevalence of Type 2 Diabetes in a Rural Bangladeshi Population: A Population Based Study for 10 Years. Diabetes Metab J. 2013;37:46-53.

21. Chow CK, Raju PK, Raju R, Reddy KS, Cardona M, Celermajer DS, et al. The prevalence and management of diabetes in rural India. Diabetes Care. 2006; 29:1717-8.

22. Hall V, Thomsen RW, Henriksen O, Lohse N. Diabetes in Sub Saharan Africa 1999-2011: epidemiology and public health implications. A systematic review. BMC Public Health. 2011:11:564.

23. Ramachandran A, Jali MV, Mohan V, Snehalatha C, Viswanathanet M. High prevalence of diabetes in an urban population in south India. BMJ. 1988: 297:587-90.

24. Ramachandran A, Snehalatha C, Baskar AD, Mary S, Kumar CK, Selvam S, et al. Temporal changes in prevalence of diabetes and impaired glucose tolerance associated with lifestyle transition occurring in the rural population in India. Diabetologia. 2004;47:860-5.

25. The World Bank. Country and Lending Groups [Internet]. 2016. Available from: http://data.worldbank.org/about/country-classifications/country-andlending-groups\#Lower_middle_income.

26. Chuang LM, Tsai ST, Huang BY, Tai TY. The status of diabetes control in Asia-a cross-sectional survey of 24317 patients with diabetes mellitus in 1998. Diabet Med. 2002;19:978-85.

27. Levitt NS. Diabetes in Africa: epidemiology, management and healthcare challenges. Heart. 2008;94:1376-82

28. Fernando DJ, Siribaddana S, Perera N, Perera S, de Silva D. The prevalence of macrovascular disease and lipid abnormalities amongst diabetic patients in Sri Lanka. Postgrad Med J. 1993;69:557-61.
29. Fernando DJ, Siribaddana S, De S, Subasinge Z. Prevalence of retinopathy in a Sri Lankan diabetes clinic. Ceylon Med J. 1993:38:120-3.

30. Fernando DJ. The prevalance of neuropathic foot ulceration in Sri Lankan diabetic patients. Ceylon Med J. 1996:41:96-8.

31. Weerasuriya N, Siribaddana S, Dissanayake A, Subasinghe Z, Wariyapola D, Fernando DJ. Longterm complications in newly diagnosed Sri Lankan patients with type 2 diabetes mellitus. Q J Med. 1998;91:1-5.

32. Weerarathna TP, Kariyawasam BDI, Welgamage T. Profile of foot problems detected by standard annual screening at a diabetic foot clinic. Galle Medical Journal. 2006;11:72.

33. Weerasuriya N, Siribaddana S, Wijeweera I, Dissanayeka A, Wijesekera J, Fernando DJ. The prevalence of peripheral neuropathy in newly diagnosed patients with non-insulin-dependent diabetes mellitus. Ceylon Med J. 1998; 43:19-21.

34. Jayaweera-Bandara C. Diabetic retinopathy, its incidence in Sri Lanka and its treatment. Transactions of the Ophthalmic Society. 1987;29:4-16.

35. Engelgau M, Okamoto K, Navaratne KV, Gopalan S. Prevention and Control of Selected Chronic NCDs in Sri Lanka: Policy Options and Action. Washington DC: The World Bank; 2010.

36. Marmot M. Social determinants of health inequalities. Lancet. 2005;365: 1099-104

37. De Silva AP, De Silva SHP, Liyanage IK, Rajapakse LC, Jayasinghe KS, Katulanda $\mathrm{P}$, et al. Social, cultural and economical determinants of diabetes mellitus in Kalutara district, Sri Lanka: a cross sectional descriptive study. Int J Equity Health. 2012;11:76

38. Rose GA. The diagnosis of ischaemic heart pain and intermittent claudication in field surveys. Bull World Health Organ. 1962;27:645-58.

39. De Silva AP. Social Determinants of Diabetes Mellitus in Kalutara District, in Postgraduate Institute of Medicine. Colombo: University of Colombo; 2010.

40. American Diabetes Association. Economic costs of diabetes in the U.S. in 2012. Diabetes Care. 2013;36:1033-46

41. Satharasinghe A. Census Department Classifies GN Divisions by Poverty. 1st ed. Department of Census and Statistics: Colombo; 2008.

42. Luepker RV, Rosamond WD, Murphy R, Sprafka JM, Folsom AR, McGovern $P G$, et al. Socioeconomic status and coronary heart disease risk factor trends. The Minnesota Heart Survey. Circulation. 1993:88:2172-9.

43. Migliacci R, Nasorri R, Ricciarini P, Gresele P. Ankle-brachial index measured by palpation for the diagnosis of peripheral arterial disease. Fam Pract. 2008; 25:228-32.

44. Ministry of Healthcare and Nutrition. National Guidelines: Diabetes Mellitus. Colombo. Ministry of Healthcare and: Nutrition; 2007.

45. The ADVANCE Collaborative Group. Intensive blood glucose control and vascular outcomes in patients with type 2 diabetes. New England Journal of Medicine. 2008:358:2560-72.

46. Benedict SR. A reagent for the detection of reducing sugars. J Biol Chem. 1909:5:485-7.

47. Jayawardena MHDS, Stenson D, Bjurman E, De Almeida TKR, Fernando DJS. The quality of care at a diabetes clinic: an audit In: Abstract book of the Sri Lanka Medical Association 115th anniversary academic sessions. Sri Lanka Medical Association: Colombo; 2002.

48. Herath HMM, Weerarathna TP, Welgamage T, Kariyawasam BDI. An audit of diabetic management in a tertiary care hospital. Galle Medical Journal. 2006;11:88.

49. Weerasuriya N. Diabetes mellitus in Sri Lanka. Sri Lanka Family Physician. 2000;23:18-20.

50. Wijesinghe MACL, Prabath API, Weerarathna TP. A study of indications for hospitalization and quality of self-care in diabetic patients admitted to Teaching Hospital Galle. Galle Medical J. 2000;2:Ab-23.

51. Katulanda P, Constantine GR, Mahesh JG, Sheriff R, Seneviratne RD, Wijeratne $\mathrm{S}$, et al. Prevalence and projections of diabetes and pre-diabetes in adults in Sri Lanka - Sri Lanka Diabetes, Cardiovascular Study (SLDCS). Diabet Med. 2008:25:1062-9.

52. Pinidiyapathirage MJ, Kasturiratne A, Ranawaka UK, Gunasekara D, Wijekoon $\mathrm{N}$, Medagoda $\mathrm{K}$, et al. The burden of diabetes mellitus and impaired fasting glucose in an urban population of Sri Lanka. Diabet Med. 2013;30:326-32.

53. De Silva AP, De Silva SHP, Haniffa R, Liyanage IK, Jayasinghe KSA, Katulanda P, Wijeratne CN, Wijeratne S, Rajapakse LC. A cross sectional survey on social, cultural and economic determinants of obesity in a low middle income setting. Int J Equity Health. 2015;14:6.

54. Marmot MG, Shipley MJ, Rose G. Inequalities in death-specific explanations of a general pattern. The Lancet. 1984;323:1003-6. 
55. Marmot M. Self esteem and health. Br Med J. 2004;327:574-5.

56. Mackenbach JP, Stirbu I, Roskam AJR, Schaap MM, Menvielle G, Leinsalu M, Kunst AE. Socioeconomic inequalities in health in 22 European countries. N Engl J Med. 2008:358:2468-81.

57. Navarro V, Muntaner C. Political and Economic Determinants of Population Health and Well-Being: Controversies and Developments. Baywood Publishing Company: New York; 2004.

58. Townsend P, Davidson N. Inequalities in Health, the Black Report and the Health Divide. 2nd ed. London: Penguin Books; 1992.

59. Rose G, Marmot MG. Social class and coronary heart disease. Br Heart J. 1981:45:13-9.

60. Samarasinghe V. Puppets on a String: Women's Wage Work and Empowerment among Female Tea Plantation Workers of Sri Lanka. J Developing Areas. 1993;27:329-40.

61. Kerr EA, Gerzoff RB, Krein SL, Selby JV, Piette JD, Curb JD, et al. Diabetes Care Quality in the Veterans Affairs Health Care System and Commercial Managed Care: The TRIAD Study. Ann Intern Med. 2004;141:272-81.

62. Saaddine JB, Cadwell B, Gregg EW, Engelgau MM, Vinicor F, Imperatore G, et al. Improvements in Diabetes Processes of Care and Intermediate Outcomes: United States, 1988-2002. Ann Intern Med. 2006;144:465-74.

63. Giachello AL, Arrom JO, Davis M, Sayad JV, Ramirez D, Nandi C, et al. Reducing diabetes health disparities through community-based participatory action research: the Chicago Southeast Diabetes Community Action Coalition. Public Health Rep. 2003;118:309-23.

64. Landon BE, Hicks LS, O'Malley AJ, Lieu TA, Keegan T, McNeil BJ, et al. Improving the Management of Chronic Disease at Community Health Centers. N Engl J Med. 2007;356:921-34.

\section{Submit your next manuscript to BioMed Central and we will help you at every step:}

- We accept pre-submission inquiries

- Our selector tool helps you to find the most relevant journal

- We provide round the clock customer support

- Convenient online submission

- Thorough peer review

- Inclusion in PubMed and all major indexing services

- Maximum visibility for your research

Submit your manuscript at www.biomedcentral.com/submit 